\title{
Investigating the Effect of Nigeria's Macroeconomic Variables on Economic Growth in the Presence of Heteroskedasticity and Structural Breaks
}

\author{
Jonathan Atsua Ikughur ${ }^{1, ~ *, ~ P a t i e n c e ~ O n u c h e ~ A g a d a ~}{ }^{1}$, Alhaji Godwin ${ }^{2}$ \\ ${ }^{1}$ Department of Mathematics/Statistics/Computer Science, College of Science, Federal University of Agriculture, Makurdi, Nigeria \\ ${ }^{2}$ Monitoring and Evaluation Division, Planning, Research and Monitoring Department, National Health Insurance Scheme, Garki, Abuja, \\ Nigeria
}

Email address:

ikughur.ja@uam.edu.ng (J. A. Ikughur), gadexx@yahoo.com (P. O. Agada), godwaji@gmail.com (A. Godwin)

${ }^{*}$ Corresponding author

\section{To cite this article:}

Jonathan Atsua Ikughur, Patience Onuche Agada, Alhaji Godwin. Investigating the Effect of Nigeria's Macroeconomic Variables on Economic Growth in the Presence of Heteroskedasticity and Structural Breaks. International Journal of Statistical Distributions and Applications. Vol. 6, No. 3, 2020, pp. 47-56. doi: 10.11648/j.ijsd.20200603.12

Received: April 14, 2019; Accepted: May 27, 2020; Published: September 10, 2020

\begin{abstract}
This study modeled the effect of Revenue, Expenditure, Foreign Direct Investment and Exchange rate on Nigerian Gross Domestic Product (obtained from CBN from 1961-2010) in the presence of heteroskedasticity on Nigeria's macroeconomic variables using the Weighted Least Squares method. Furthermore, it investigated the changing structures in the data using Bai and Perron structural breaks approach. Results showed the existence of heteroskedasticity and the model with correction for heteroskedasticity shows that Revenue, Expenditure, Foreign Direct Investment provides a positive and significant effect on GDP while the Exchange rate negatively affect the GDP while the model with heteroskedasticity showed that Revenue, Expenditure, Foreign Direct Investment significantly affect GDP positively while Exchange rate has negative effect on the GDP. The model with correction for heteroskedasticity is by far more efficient than the model with heteroskedasticity as evidenced by the information as well as other adequacy criteria. Finally, the Bai-Perron Multiple Breakpoint Test identified five (5) breaks within this periods namely; 1973, 1980, 1987, 1994 and 2001 and this persistent break is not healthy for economic growth of Nigeria.
\end{abstract}

Keywords: Model, Macroeconomic Variables, Heteroskedasticity, Structural Breaks

\section{Introduction}

One of the primary responsibility of any government world over is to ensure that her citizens are secured, enjoy freedom and have good welfare scheme among others. To carry out these among other subsidiary functions, governments need adequate funding. Unfortunately, the size, structure and growth of government expenditure have increased tremendously and become increasingly large over the years especially in developing countries as a result of growing population of citizens and low technological development. In Nigeria for instance, the Population and H1ousing Census of 2006 put the population at $140,431,790$ and this increased to $181,403,148$ in the year 2014 with a growth rate of $3.2 \%$ between 2006 and 2014 [1].
Nigeria as a country is located in West Africa. It lies between $41.6^{\circ}$ and $13.53^{\circ}$ North of Latitude and $2.40^{\circ}$ and $14.41^{\circ}$ East of Longitude and is bordered in the West, North, East and South by Republic of Benin, Niger, Chad and Cameroun and Atlantic Ocean respectively.

The governments in Nigeria depends so much on oil revenue for execution of its primary functions and economic development programmes. Oil prices and hence, oil revenue is determined by foreign exchange which is influenced by forces of demand and supply just like the general commodity market system. Thus exchange rate is affected by the factors such as relative prices of the commodities, rate of inflation, and interest rates.

The nature of the Nigerian economy that hindered the pace of her economic development has necessitated the demand 
for foreign direct investment into the country for which the government of Nigeria has taken a some measures necessary to attract foreign investors into Nigeria. These measures included the repeal of laws that are inimical to foreign investment growth, promulgation of investment laws, various oversea trips for image laundry among others.

The dwindling revenue and increased cost of running government require all tiers of government in Nigeria to look for alternative means of improving her Gross Domestic Product. Obviously, the country's revenue from oil can no longer fully supports government development objectives as such, it becomes imperative to provide information on the effect of some economic variable on Nigerian Gross Domestic Product.

Works on modeling the effect of revenue and expenditure on gross domestic product include that of [2]. In their study on effect of expenditure on economic growth used panel data for fourteen (14) developed countries for a period ranging from 1970 to 1990 and applied the ordinary least square method on 5-year moving average. They took various functional types of expenditure (health, education, transport, etc) as explanatory variables and found that health, transport and communication have significant positive effect while education and defense have a negative impact on economic growth.

To investigate the relationship between budgetary operation and economic growth, the study [3] regressed gross domestic product on six-predictor variables including Oil Revenue, Non-Oil Revenue, Administrative Expenditure, Economic Expenditure, Social Expenditure and Transfer Expenditure of period each spanning thirty-seven years. Using the error correction model approach, he showed the inability of oil revenue to strongly cause an increase in the output level of gross domestic product in the short-run is occasioned by the fact that most equipment, technology, fund and even expert manpower used in the oil sector are imported.

Similarly, the impact of government spending on economic growth was investigated by the study [4] using ordinary least square and generalized least square methods and found that productive public expenditures enhance economic growth, but non-productive public spending does not.

Linear regression model was fit on data obtained from Central Bank of Nigeria's publication by the study [5] who reported a positive effect of capital expenditure, recurrent expenditure, oil revenue and federation retained revenue on economic growth for the long-run modeling and positive impact of capital expenditure, oil revenue, federation account and federal retained revenue on economic growth for the short-run modeling. The study recommends a re-evaluation and re-assessment of direction of recurrent expenditure and non-oil revenue towards Nigerian development to achieve positive influence on economic growth.

The effect of public expenditure on economic growth in Nigeria for the period 1970 - 2009 was investigated by the studies [6] and [7] who applied ordinary least square multiple regression model data extracted from the statistical Bulletin of the Central Bank of Nigeria. They reported that capital and recurrent expenditure on economic services had insignificant negative effect on economic growth during the study period.

On the impact of exchange rate on economic growth, the study [8] employed correlation and regression analyses on the data spanning the year 1986 to 2013 sourced from Central Bank of Nigeria statistical bulletin of various issues. The result revealed that exchange rate has positive impact but not significant. The result also indicated that interest rate and rate of inflation have negative impact on economic growth but not significant. In the same way, [9] employed multiple regressions model using ordinary least squared method to test the impact of exchange rate on the economic growth in Sri Lanka. Annual time series data from 1970 to 2015 were used and the variables such as gross domestic product, exchange rate, inflation rate and interest rate were considered. The outcome of the multiple regression model confirmed that exchange rate has a positive influence on the economic growth in Sri Lanka at one percent level of significant.

In their study [10], they employed growth model via the ordinary least square method to investigate the relationship between foreign direct investment (FDI) and economic growth in Nigeria. Their work covered a period of twenty eight years (1981-2009) using an annual data from Central Bank of Nigeria statistical bulletin. The study also added gross fixed capital formation (GFCF) with a view to capture the effect of domestic investment on the growth of the economy for the period under review. Interest rate and exchange rate were also added as control variables in the model. The result of the ordinary least square techniques indicated that FDI has a positive and insignificant impact on the growth of Nigerian economy for the period under study.

The impact of foreign direct investment on Nigeria economic growth over the period of 1999-2013 was investigated by the study [11] using secondary data sourced from various publications of Central Bank of Nigeria, such as; statistical bulletin, annual reports and statement of accounts. The study employed regression analysis of the ordinary least square and revealed that economic growth is directly related to inflow of foreign direct investment and it is also statistically significant at 5\% level which implies that a good performance of the economy is a positive signal for inflow of foreign direct investment. In the same manner, [12] evaluated the impact of foreign direct investment (FDI) on the economic development of Bangladesh by conducting statistical analysis of the relationship between FDI and its impact on selected macroeconomic indicators such as gross domestic product, inflation rate and balance of trade using time series data over a period of fifteen years, from 1999 to 2013 and multiple regression analysis. The study disclosed a negative correlation between FDI and economic growth and may be a concern for the government of Bangladesh. The government might focus on required reforms and policy implications to make foreign investment more beneficial.

On heteroskedasticity, studies including work by the study [13] argued that though weighted least square (WLS) procedure is an efficient estimation if the exact form of heteroskedasticity is known, it is not easy to determine the 
exact form of heteroskedasticity in most cases. He also disclosed that the general form of the heteroskedastic regression model has too many parameters to estimate by ordinary methods in order to achieve feasible generalized least square (FGLS) estimator. In order to resolve the problem of finding consistent estimators of the unknown parameters in the model, he proposes two methods: two-step GLS estimation and two-step maximum likelihood estimation.

In the same manner, the study [14] disclosed that if heteroskedasticity is detected using one of the tests, one possible response is to use heteroskedasticity-robust statistics after estimation by ordinary least square (OLS). He presented that another response to a finding of heteroskedasticity is to specify its form and use weighted least squares (WLS) approach. He argued that if we have correctly specified the form of heteroskedasticity, then WLS is more efficient than OLS and WLS leads to new $t$ and $f$ statistics that have $t$ and $F$ distributions. He proposed the modeling or estimation of heteroskedasticity, use data to estimate the unknown parameter in the model and then use the WLS procedure. He termed this approach as feasible generalized least square (FGLS) or estimated generalized least square (EGLS).

In the case of structural breaks, the study [15] considered issues related to multiple structural changes, occurring at unknown dates in the linear regression model estimated by least squares. The main aspects of their work are the properties of the estimators, including the estimates of the break dates and the construction of tests that allow inference to be made about the presence of structural change and the number of breaks.

A novel statistic for conducting joint tests on all the structural parameters in instrumental variables regression was proposed by the study [16]. The statistic equals a quadratic form of the score of the concentrated log-likelihood and straightforward to compute. It therefore attains its minimal value equal to zero at the maximum likelihood estimator. The statistic has a $\chi^{2}$ limiting distribution with a degrees of freedom parameter equal to the number of structural parameters.

A modification to the methodology adopted by the study [18] to investigate structural breaks in small samples was performed by the study [17]. They used Monte Carlo simulations to determine sample-specific critical values under the null each time the test is run. They draw on the results of their simulations to offer practical suggestions on handling serial correlation, model misspecification and the use of alternative test statistics for sequential testing. They revealed that for most types of data generating processes in samples with as low as 50 observations, their proposed modifications perform substantially better.

A consistent test for smooth structural changes which may be more realistic in economics than abrupt breaks was proposed by the study [19]. Their aim was to verify the observation by [20] who pointed out that it may seem unlikely that a structural break could be immediate and might seem more reasonable to allow a structural change to take a period of time to take effect. However, the study [21] introduces ideas and methods for testing for structural change in linear regression models and presents how these have been realized in an $\mathrm{R}$ package called strucchange. They features tests from the generalized fluctuation test framework as well as from the $\mathrm{F}$ test (Chow test) framework. Extending standard significance tests it contains methods to fit, plot and test empirical fluctuation process (like CUSUM, MOSUM and estimates-based processes) on the one hand and to compute, plot and test sequences of F statistics with the SupF, aveF and expF test on the other.

To examines the structural break dates for export, import and GDP in Ethiopia using annual macreconomic time series data spanning the years from 1974 through 2009, the study [22] used Chow test which was formalized from the study [23] to perform tests on the time series data on three assumed dates 1992, 1993, and 2003 to determine the date (s) at which there was a statistically significant structural break. They discovered that Ethiopia economy has been subjected to a structural break and regime shift during the sample period. They also infers that endogenously determined structural break time for the macroeconomic variables (export, import and GDP) of Ethiopian economy was found to be 2003 .

To test for multiple structural breaks, the study [24] utilized the methodology developed by [15] on Turkish 90 days' time deposits interest rate and consumer price index inflation rate over the period of 1980: 1-2004:12. The empirical results provided a little evidence of mean breaks in the interest rate series. However, the data on inflation rates is consistent with two breaks that are located at 1987: 9 and 2000:2

The essence of investigating the effect of revenue, expenditure, foreign direct investment and exchange rate on Nigerian Gross Domestic Product is to provide a model that explains the behavior of the variables under consideration that will assist in policies for help to boosting Gross Domestic Product. However, modeling these variables using the classical regression model leads to inefficient estimates. Furthermore, because of the changing government, changing policies and market forces, structural breaks occurs and these breaks have their impact on the predictive ability of the model. This study therefore, focuses on modeling the effect of revenue, expenditure, foreign direct investment and exchange rate on Nigerian gross domestic product obtained from Central Bank of Nigeria Bulletin of 2012 covering the period 1961-2010. It uses regression model with and without correction for heteroskedasticity and finally, performs investigation of structural breaks on the models under study.

\section{Methods}

\subsection{Regression Model}

The specification of linear regression model with four explanatory variables is given as

$$
Y=\beta_{0}+\beta_{1} X_{1}+\beta_{2} X_{2}+\beta_{3} X_{3}+\beta_{4} X_{4}+u
$$

where $Y$ is the GDP, $X_{1}$ is the revenue, $X_{2}$ is the expenditure, $X_{3}$ is the foreign direct investment, $X_{4}$ is the exchange rate, $\beta_{0}, \beta_{1}, \beta_{2}, \beta_{3}$ and $\beta_{4}$ are the parameters and $u$ is the error 
term. Here, it is assumed that $u_{i} \sim N\left(0, \sigma_{u}^{2}\right), \operatorname{cov}\left(u_{i}, u_{j}\right)=0$, $\operatorname{cov}\left(X_{i}, X_{j}\right)=0$ so that by ordinary least squares the estimators of the regression parameters $\beta_{0}, \beta_{1}, \beta_{2}, \beta_{3}$ and $\beta_{4}$ is given as:

$$
\hat{\beta}=\left(X^{\prime} X\right)^{-1} X^{\prime} y
$$

with

$$
\operatorname{cov}(\hat{\beta})=\hat{\sigma}^{2}\left(X^{\prime} X\right)^{-1}
$$

Where $\hat{\sigma}^{2}$ is the estimated mean square error.

\subsection{Test for Heteroskedasticity of Error Terms: The White Test}

Consider model (1) whose auxiliary model is

$$
u_{t}^{2}=\alpha_{0}+\alpha_{1} X_{t}+\alpha_{2} X_{t}^{2}+v_{t}
$$

The unadjusted $R_{u^{2}}^{2}$ is given as

$$
R_{u^{2}}^{2}=\frac{S S R u^{2}}{S S T u^{2}}
$$

The Lagrange Multiplier (LM) test statistic is

$$
L M=n \cdot R_{u^{2}}^{2}
$$

where $S S R_{u^{2}}=\alpha^{\prime}\left(X^{\prime} u^{2}\right)-\frac{\left(\Sigma u^{2}\right)^{2}}{n}, S S T_{u^{2}}=u^{2^{\prime}} e^{2}-\frac{\left(\Sigma u^{2}\right)^{2}}{n}$ and $\hat{\alpha}=\left(X^{\prime} X\right)^{-1} X^{\prime} u^{2}$. The hypothesis of homoscedasticity of error terms against error terms not homoscedastic is given $H_{0}: \alpha_{1}=\alpha_{2}=0$ vs $H_{1}: \alpha_{1} \neq \alpha_{2} \neq 0$ such that the LM statistic follows a $\chi_{\alpha, p-1}^{2}$ distribution with $p-1$ degrees of freedom and $\alpha$ level of significance; where $p$ is the number of parameters in the auxiliary regression. In this case, we reject $H_{0}$ if $n . R_{u^{2}}^{2}>\chi_{\alpha, p-1}^{2}$. However, If $H_{0}$ is not rejected, it implies that residuals are homoscedastic. This test has been found useful in samples of 30 or more

\subsection{Corrections for Heteroskedasticity in Linear \\ Regression Model When its Form is Unknown}

Consider the general specification of linear regression model defined in Equation (1) and the general case of heteroskedasticity where $\operatorname{var}\left(u_{i} \mid X_{i}\right)=\sigma_{i}^{2}=\sigma^{2} \Omega=\sigma^{2} w_{i}$. To correct this inefficiency of OLS estimators, the Generalized (or Weighted) Least Squares (GLS or WLS) estimator is used. Here, we let

$$
\begin{gathered}
X=\left[\begin{array}{cccc}
1 & x_{11} & \ldots & x_{n 1} \\
1 & x_{12} & \ldots & x_{n 1} \\
\vdots & \vdots & \vdots & \vdots \\
1 & x_{1 n} & \ldots & x_{n n}
\end{array}\right] \text { and } y=\left[\begin{array}{c}
y_{1} \\
y_{2} \\
\vdots \\
y_{n}
\end{array}\right], \\
p=\left[\begin{array}{ccccc}
\sqrt{w_{1}} & 0 & \ldots & 0 \\
0 & \frac{1}{\sqrt{w_{2}}} & \ldots & 0 \\
\vdots & \vdots & \vdots & \vdots \\
0 & 0 & \ldots & \frac{1}{\sqrt{w_{n}}}
\end{array}\right]
\end{gathered}
$$

where $p$ is a square (nxn) matrix whose $i^{\text {th }}$ diagonal element is $\frac{1}{\sqrt{w_{i}}}$.

Therefore,

$$
p^{\prime} p=\left[\begin{array}{cccc}
\frac{1}{w_{1}} & 0 & \ldots & 0 \\
0 & \frac{1}{w_{2}} & \ldots & 0 \\
\vdots & \vdots & \vdots & \vdots \\
0 & 0 & \ldots & \frac{1}{w_{n}}
\end{array}\right]
$$

Hence, $\Omega^{-1}=p^{\prime} p$. By pre-multiplying $p$ on y and $\mathrm{X}$, we get

$$
y^{*}=p y=\left[\begin{array}{c}
y_{1} \\
\sqrt{w_{1}} \\
\frac{y_{2}}{\sqrt{w_{2}}} \\
\vdots \\
\frac{y_{n}}{\sqrt{w_{n}}}
\end{array}\right]
$$

and

$$
X^{*}=p X=\left[\begin{array}{cccc}
\frac{1}{\sqrt{w_{1}}} & \frac{x_{11}}{\sqrt{w_{1}}} & \cdots & \frac{x_{1 k}}{\sqrt{w_{1}}} \\
\frac{1}{\sqrt{w_{2}}} & \frac{x_{21}}{\sqrt{w_{2}}} & \cdots & \frac{x_{2 k}}{\sqrt{w_{2}}} \\
\frac{1}{\sqrt{w_{n}}} & \frac{x_{n 1}}{\sqrt{w_{n}}} & \cdots & \frac{x_{n k}}{\sqrt{w_{n}}}
\end{array}\right]
$$

So that the GLS estimator can be obtained by regressing $y^{*}$ on $X^{*}$.

Thus, the GLS estimator of $\beta$ is given as

$$
\hat{\beta}=\left(X^{\prime} \Omega^{-1} X\right)^{-1} X^{\prime} \Omega^{-1} y
$$

Where $\Omega^{-1}$ is a diagonal matrix whose $i^{\text {th }}$ diagonal element is $\frac{1}{w_{i}}$. The Weighted Least Squares (WLS) estimator is obtained by applying Ordinary Least Squares to the GLS estimator, thus

$$
\hat{\beta}=\left[\sum_{i=1}^{n} w_{i} X_{i} X_{i}^{\prime}\right]^{-1}\left[\sum_{i=1}^{n} w_{i} X_{i} y_{i}\right]
$$

Each squared residual is weighted by $\frac{1}{w_{i}}$ i.e. $\sigma_{i}{ }^{2}=\frac{1}{w_{i}}$ or $=$ $\frac{1}{\sigma_{i}^{2}}$.

If the variance is proportional to the square of one of the regressors i.e. $\sigma_{i}{ }^{2}=\sigma^{2} x_{i k}^{2}$, then the transformed regression model for GLS is

$$
\frac{y}{x_{k}}=\beta_{k}+\beta_{1}\left(\frac{x_{1}}{x_{k}}\right)+\beta_{2}\left(\frac{x_{2}}{x_{k}}\right)+\cdots+\frac{u}{x_{k}}
$$

where $\beta_{k}=\beta_{0} / x_{k}$. If the variance is proportional to one of the regressors, i.e $\sigma_{i}^{2}=\sigma^{2} x_{i k}$, then the transformed regression model for GLS is

$$
\frac{y}{x_{k}}=\beta_{k}+\beta_{1}\left(\frac{x_{1}}{\sqrt{x_{k}}}\right)+\beta_{2}\left(\frac{x_{2}}{\sqrt{x_{k}}}\right)+\cdots+\frac{u}{\sqrt{x_{k}}}
$$

Where $\beta_{k}=\beta_{0} / \sqrt{x_{k}}$.

In most cases, it is difficult to determine the exact form of 
heteroskedasticity but can be estimated. Thus $w_{i}$ is estimated by $\widehat{w}_{i}$, giving rise to feasible GLS (FGLS) estimator which is sometimes called estimated GLS or EGLS whose parameters are estimated by

$$
\hat{\beta}_{F G B S}=\left(X^{\prime} \widehat{\Omega}^{-1} X\right)^{-1} X^{\prime} \widehat{\Omega}^{-1} y
$$

\subsection{Regression Model with Structural Break Model}

Structural break is the sudden changes in time series data or regression parameter as a result of changes in government policy, serious disaster or civil war among others. Let the sample period be $t=1, \ldots, n$, has break-date as $T_{1}$; break date fraction $\tau_{1}=T_{1} / n$, pre-break sample as $t=1, \ldots, T_{1}\left(T_{1}\right.$ observations) and post-break sample be $t=T_{1}+1, \ldots, n$; $n-T_{1}$ observations. Then, the full structural break model is represented as

$$
\left.\begin{array}{l}
y_{t}=\beta_{1}^{\prime} X_{t}+u_{t}, t \leq T_{1} \\
y_{t}=\beta_{2}^{\prime} X_{t}+u_{t} t>T_{1}
\end{array}\right\}
$$

or $y_{t}=\beta_{1}^{\prime} X_{t 1}\left(t \leq T_{1}\right)+\beta_{2}^{\prime} X_{t 2}\left(t>T_{1}\right)+u_{t}$ while the partial structural break model is

$$
y_{t}=\beta_{0}^{\prime} Z_{t}+\beta_{1}^{\prime} X_{t 1}\left(t \leq T_{1}\right)+\beta_{2}^{\prime} X_{t 2}\left(t>T_{1}\right)+u_{t}
$$

Similarly, for the general model

$$
y_{t}=\beta^{\prime} X_{t}+u_{t}
$$

The variance break model is represented as $\operatorname{var}\left(u_{t}\right)=$ $\sigma_{1}^{2}, t \leq T_{1}, \operatorname{var}\left(u_{t}\right)=\sigma_{2}^{2}, t>T_{1}$

It is worth to note that breaks do not necessarily affect point forecasts but rather, they affect forecast variance, intervals, and densities and so on.

\subsection{Identification of Multiple Structural Breaks}

Basically, Model stability is very important for statistical inference appropriate inference, out-of-sample forecasts, and any policy implications drawn from the model. Moreover, the existence of relatively constant linear relationships between economic variables is important for model parameters to be regarded as marginal propensities or elasticities. Such economic interpretations will be invalid in the presence of structural breaks. Therefore, detection and identification of structural breaks are important.

The test for investigation of multiple structural breaks was proposed by [15]. Their methodology considered the following multiple structural break model with $\mathrm{m}$ breaks or $(\mathrm{m}+1)$ regimes

$$
\left.\begin{array}{c}
y_{t}=x_{t}^{\prime} \beta+Z_{t}^{\prime} \delta_{1}+u_{t} ; t=1, \ldots, T_{1} \\
y_{t}=x_{t}^{\prime} \beta+Z_{t}^{\prime} \delta_{2}+u_{t} ; t=T_{1}+1, \ldots, T_{2} \\
\vdots \vdots \vdots \\
y_{t}=x_{t}^{\prime} \beta+Z_{t}^{\prime} \delta_{m+1}+u_{t} ; t=T_{m}+1, \ldots, T
\end{array}\right\}
$$

where $y_{t}$ is the observed dependent variable at time t; $x_{t}(p \times 1)$ and $z_{t}(q \times 1)$ are vectors of covariates, $\beta$ and $\delta_{j}(j=1, \ldots, m+1)$ are the corresponding vectors of coefficients; and $u_{t}$ is the disturbance term at time t. the break points $\left(T_{1}, \ldots, T_{m}\right)$ are treated as unknown, and are estimated together with the unknown coefficients when $T$ observations are available. The aim is to estimate the unknown regression coefficients and the break dates $\left(\beta, \delta_{1}, \ldots, \delta_{m+1}, T_{1}, \ldots, T_{m}\right)$ when $T$ observations on $\left(y_{t}, x_{t}, z_{t}\right)$ are available. In Matrix representation,

$$
Y=X \beta+\bar{Z} \delta+u
$$

where $\quad Y=\left(y_{1}, \ldots, y_{T}\right)^{\prime} \quad, \quad X=\left(x_{1}, \ldots, x_{T}\right)^{\prime}$, $U=\left(u_{1}, \ldots, u_{T}\right)^{\prime} \delta=\left(\delta_{1}{ }^{\prime} \delta_{1}{ }^{\prime}, \ldots, \delta_{m+1}{ }^{\prime}\right)^{\prime}$, and $\bar{Z}$ is the matrix which diagonally partitions $Z$ at the m-partition $\left(T_{1}, \ldots, T_{m}\right)$, i.e., $\bar{Z}=\operatorname{diag}\left(Z_{1}, \ldots, Z_{m+1}\right)$ with $Z_{i}=\left(Z_{T_{i-1}+1}, \ldots, Z_{T_{i}}\right)^{\prime}$.

The estimation method considers is based on the squares principle proposed by [15]. Thus, for each mpartition $\left(T_{1}, \ldots, T_{m}\right)$, denoted by $\left\{T_{j}\right\}$, the associated least squares estimate of $\delta_{j}$ is obtained by minimizing the sum of squares residuals $\sum_{i=1}^{m+1} \sum_{t=T_{i-1}+1}^{T_{i}}\left(y_{t}-Z_{t}{ }^{\prime} \delta_{i}\right)^{2}$. Let $\hat{\delta}\left(\left\{T_{j}\right\}\right)$ denote the resulting estimate. Substituting it in the objective function and denoting the resulting sum of squared residuals as $S_{T}\left(T_{1}, \ldots, T_{m}\right)$, the estimated break dates $\left(\widehat{T}_{1}, \ldots, \widehat{T}_{m}\right)$ are such that

$$
\left(\left(\widehat{T}_{1}, \ldots, \widehat{T}_{m}\right)\right)=\arg \min _{\left(T_{1}, \ldots, T_{m}\right)} S_{T}\left(T_{1}, \ldots, T_{m}\right)
$$

When the minimization is taken over all partitions $\left(T_{1}, \ldots, T_{m}\right)$ such that $T_{i}-T_{i-1} \geq[\varepsilon T]^{2}$. Note that $[\varepsilon T]$ is the minimal number of observations in each segment. Thus the break points estimators are global minimizers of the objective function. Finally, the regression parameter estimates are the associated least-squares estimates at the estimated $\mathrm{m}$ partition $\left\{\widehat{T}_{j}\right\}$, i.e. $\hat{\delta}\left(\left\{T_{j}\right\}\right)$.

[15] first consider the Sup $F$ type test of no structural break $(m=0)$ against the alternative hypothesis that there are $m=k$ breaks. Here, we let $\left(T_{1}, \ldots, T_{m}\right)$ be a partition such that $T_{i}=\left[T \lambda_{i}\right] \Rightarrow \lambda_{i}=\frac{T_{i}}{T}, i=1, \ldots, k$. Then the test is given as

$$
F_{T}\left(\lambda_{1}, \ldots, \lambda_{K} ; q\right)=\left(\frac{T-(k+1) q-p}{k q}\right) \frac{\widehat{\delta}^{\prime} R^{\prime}\left(R\left(\bar{Z}^{\prime} M_{X} \bar{Z}\right)^{-1} R^{\prime}\right)^{-1} R \widehat{\delta}}{S S R_{K}}
$$

Where $R$ is the conventional matrix such that $(R \delta)^{\prime}=$ $\left(\delta_{1}{ }^{\prime}-\delta_{2}{ }^{\prime}, \ldots, \delta_{k}{ }^{\prime}-\delta_{k+1}{ }^{\prime}\right)$ and

$M_{X}=I-\left(X^{\prime} X\right)^{-1} X^{\prime} y$. Here $S S R_{K}$ is the sum of squared residuals under the alternative hypothesis, which depends on $\left(T_{1}, \ldots, T_{k}\right)$. In order to carry out the asymptotic analysis, they imposed some restrictions on the possible values of the break dates. In particular, they defined the following set for some arbitrary small possible number

$$
\epsilon: \Lambda_{\epsilon}=\left\{\left(\lambda_{1}, \ldots, \lambda_{k}\right) ;\left|\lambda_{i+1}-\lambda_{i}\right| \geq \epsilon, \lambda_{1} \geq \epsilon, \lambda_{k} \leq 1-\epsilon\right\}
$$

The sup F type test statistic is then define as

$$
\sup F_{T}(k ; q)=\sup _{\left(\lambda_{1}, \ldots, \lambda_{k}\right) \epsilon \Lambda_{\epsilon}} F_{T}\left(\lambda_{1}, \ldots, \lambda_{k} ; q\right)
$$

which is a generalization of the sup F test considered by [24] among others for the case $k=1$. 


\section{Results}

Result from the White tests for the presence of heteroskedasticity is shown on Table 1 while Tables 2 and 3 respectively, show the estimated parameter of the regression model in the presence of heteroskedasticity and also, the estimated model parameter when heteroskedasticity is corrected. Table 4 presents the Bai-Perron multiple breakpoint tests with sequentially determined breaks 1973 , 1980, 1987, 1994 and 2001 while Table 5 shows the BaiPerron breaks Test statistics employ with HAC covariances assuming common data distribution.

Table 1. Breusch-Godfrey Serial Correlation LM Test and White Test for Heteroskedasticity.

\begin{tabular}{llll}
\hline F-statistic & 94359.45 & Prob. F (10, 10) & 0.0000 \\
Obs*R-squared & 49.99947 & Prob. Chi-Squares (10) & 0.0000 \\
\hline
\end{tabular}

Test for Heteroskedasticity.

Test statistic: $\mathrm{LM}=21.3112$.

p-value $=0.000707397$.

Table 2. Estimated Parameter of regression model in the Presence of Heteroskedasticity.

\begin{tabular}{llllll}
\hline & Coefficient & Std. Error & t-ratio & p-value & \\
\hline Const & -117334 & 143587 & -0.8172 & 0.41814 & $* * *$ \\
REV & 0.943019 & 0.262159 & 3.5971 & 0.00080 & $* 0.00001$ \\
EXPDT & 5.36869 & 0.569786 & 9.4223 & 0.04990 & $* *$ \\
FDI & 0.421656 & 0.209253 & 2.0151 & 0.07697 & $*$ \\
EXCHRATE & -11993.9 & 6626.31 & -1.8100 & & $*$ \\
\hline
\end{tabular}

\begin{tabular}{llll}
\hline Mean dependent Var & $\mathbf{3 8 0 2 1 9 1}$ & S. D. dependent Var & $\mathbf{7 7 6 2 4 5 3}$ \\
\hline Sum squared resid & $3.25 \mathrm{e}+13$ & S. E. of regression & 849261.4 \\
R-squared & 0.989007 & Adjusted R-squared & 0.988030 \\
F $(4,45)$ & 1012.164 & P-value (F) & $1.96 \mathrm{e}-43$ \\
Log-likelihood & -750.9190 & Akaike criterion & 1511.838 \\
Schwarz criterion & 1521.398 & Hannan-Quinn & 1515.479 \\
Rho & -0.006536 & Durbin-Watson & 1.739178 \\
\hline
\end{tabular}

Dependent variable: GDP.

Legend: REV=Revenue, EXPDT=Expenditure, FDI=Foreign Direct Investment and EXCHRATE=Exchange Rate. Level of significance is equal to $\alpha<0.05$.

Table 3. Estimated Model Parameter with Correction for Heteroskedasticity using Weighted Least Squares (WLS).

\begin{tabular}{llllll}
\hline & Coefficient & Std. Error & t-ratio & p-value & \\
\hline Const & 1383.85 & 17620.7 & 0.0785 & 0.93775 & \\
REV & 1.22765 & 0.242247 & 5.0677 & $<0.00001$ & $* * *$ \\
EXPDT & 4.37859 & 0.658877 & 6.6455 & $<0.00001$ & $* * *$ \\
FDI & 0.599315 & 0.218382 & 2.7443 & 0.00868 & $* * *$ \\
EXCHRATE & -14280.5 & 5808.5 & -2.4586 & 0.01786 & $* *$ \\
\hline
\end{tabular}

\begin{tabular}{llll}
\hline \multicolumn{2}{l}{ Statistics based on the weighted data } & & \\
\hline Sum squared resid & 38.16635 & S. E. of regression & 0.920946 \\
R-squared & 0.990672 & Adjusted R-squared & 0.989843 \\
F $(4,45)$ & 1194.762 & P-value (F) & 4.87 e- 45 \\
Log-likelihood & -64.19521 & Akaike criterion & 138.3904 \\
Schwarz criterion & 147.9505 & Hannan-Quinn & 142.0310 \\
Rho & -0.053126 & Durbin-Watson & 1.660446 \\
\hline
\end{tabular}

\begin{tabular}{llll}
\hline Statistics based on the original data & & & \\
\hline Mean dependent Var & 3802191 & S. D. dependent Var & 7762453 \\
Sum squared resid & $3.53 \mathrm{e}+13$ & S. E. of regression & 885427.7 \\
\hline
\end{tabular}

Dependent variable: GDP.

Table 4. Bai-Perron Multiple Breakpoint Tests.

\begin{tabular}{lllll}
\hline Variable & Coefficient & Std. Error & t-Statistic & Prob. \\
\hline $\begin{array}{l}1961-1972-12 \text { observations } \\
\text { C }\end{array}$ & -54891.00 & 30161.10 & & \\
\hline
\end{tabular}




\begin{tabular}{|c|c|c|c|c|}
\hline Variable & Coefficient & Std. Error & t-Statistic & Prob. \\
\hline EXPDT & 2.943283 & 0.479137 & 6.142879 & 0.0000 \\
\hline EXCHRATE & 78189.16 & 41469.75 & 1.885450 & 0.0740 \\
\hline REV & 0.750854 & 0.674787 & 1.112728 & 0.2790 \\
\hline FDI & 1.805417 & 1.793994 & 1.006368 & 0.3263 \\
\hline \multicolumn{5}{|c|}{1973 - 1979 -- 7 observations } \\
\hline $\mathrm{C}$ & -80012.28 & 24309.17 & -3.291444 & 0.0036 \\
\hline EXPDT & 0.187465 & 0.606729 & 0.308977 & 0.7605 \\
\hline EXCHRATE & 121770.0 & 36039.26 & 3.378816 & 0.0030 \\
\hline REV & 3.983262 & 0.276362 & 14.41319 & 0.0000 \\
\hline FDI & 0.471200 & 0.664480 & 0.709126 & 0.4864 \\
\hline \multicolumn{5}{|c|}{1980 - 1986 -- 7 observations } \\
\hline $\mathrm{C}$ & -17436.69 & 4103.097 & -4.249641 & 0.0004 \\
\hline EXPDT & -1.537138 & 0.268756 & -5.719453 & 0.0000 \\
\hline EXCHRATE & 89707.21 & 3635.156 & 24.67768 & 0.0000 \\
\hline REV & 2.214733 & 0.365412 & 6.060922 & 0.0000 \\
\hline FDI & 0.315344 & 0.082312 & 3.831106 & 0.0010 \\
\hline \multicolumn{5}{|c|}{1987 - 1993 -- 7 observations } \\
\hline $\mathrm{C}$ & 53468.84 & 30599.07 & 1.747401 & 0.0959 \\
\hline EXPDT & 2.354515 & 1.368744 & 1.720200 & 0.1008 \\
\hline EXCHRATE & -15156.91 & 22204.73 & -0.682598 & 0.5027 \\
\hline REV & 1.837683 & 0.292892 & 6.274264 & 0.0000 \\
\hline FDI & 0.427720 & 0.378796 & 1.129158 & 0.2722 \\
\hline \multicolumn{5}{|c|}{1994 - 2000 -- 7 observations } \\
\hline $\mathrm{C}$ & 1102236. & 241575.2 & 4.562701 & 0.0002 \\
\hline EXPDT & -0.964467 & 1.098639 & -0.877875 & 0.3904 \\
\hline EXCHRATE & -34278.64 & 23756.69 & -1.442905 & 0.1645 \\
\hline REV & 3.288322 & 1.446387 & 2.273473 & 0.0342 \\
\hline FDI & 0.895754 & 0.132223 & 6.774589 & 0.0000 \\
\hline \multicolumn{5}{|c|}{2001 - 2010 -- 10 observations } \\
\hline $\mathrm{C}$ & -19448097 & 3079167. & -6.316026 & 0.0000 \\
\hline EXPDT & 5.369923 & 0.661166 & 8.121899 & 0.0000 \\
\hline EXCHRATE & 170050.0 & 25863.82 & 6.574820 & 0.0000 \\
\hline REV & -0.052843 & 0.248251 & -0.212863 & 0.8336 \\
\hline FDI & 0.649835 & 0.320302 & 2.028820 & 0.0560 \\
\hline R-squared & 0.998527 & Mean dependent var & & 3802191. \\
\hline Adjusted R-squared & 0.996392 & S. D. dependent var & & 7762453. \\
\hline S. E. of regression & 466269.3 & Akaike info Crite & & 29.22662 \\
\hline Sum squared resid & $4.35 \mathrm{E}+12$ & Schwarz Crite & & 30.37384 \\
\hline Log likelihood & -700.6656 & Hannan-Quinn Crite & & 29.66349 \\
\hline F-statistic & 467.6084 & Durbin-Watson stat & & 1.984678 \\
\hline Prob (F-statistic) & 0.000000 & & & \\
\hline
\end{tabular}

Estimated number of breaks: 5 Dependent variable: GDP.

Table 5. Bai-Perron Breaks Test Statistics with HAC Covariances Assuming Common Data Distribution.

\begin{tabular}{llll}
\hline \multicolumn{2}{l}{ Sequential F-statistic determined breaks: $\mathbf{5}$} & & $\mathbf{5}$ \\
\hline Break Test & F-statistic & F-statistic & Value \\
\hline 0 vs. ${ }^{* *}$ & 102.1626 & 510.8129 & 18.23 \\
1 vs. $*$ & 32.85846 & 164.2923 & 19.91 \\
2 vs. $3 *$ & 10.04348 & 50.21739 & 20.99 \\
3 vs. 4 & 112.8911 & 564.4556 & 21.71 \\
4 vs. $5 *$ & 8.674255 & 43.37127 & 22.37 \\
\hline
\end{tabular}

* Significant at the 0.05 level.

** Bai-Perron Critical Values.

\section{Discussion}

Results on Table 1 shows the White test for heteroskedasticity. Here, the hypothesis of constant variance is rejected with $F=94359.45(P=0.0000<0.05)$ implying the presence of heteroskedasticity. The regression model in the presence of heteroskedasticity on Table 2 is represented as 


$$
\begin{aligned}
\widehat{G D P}_{i}= & -117334+0.943019 X_{1 i}+5.36869 X_{2 i} \\
& +0.421656 X_{3 i}-11993.9 X_{4 i} .
\end{aligned}
$$

This results shows that Revenue, Expenditure, Foreign Direct Investment have significant positive effect on GDP since the $P<0.05$ ) while Exchange rate has negative but non-significant affect GDP. This result to some extent, agrees with the works of $[7,11]$.

However, when we consider the regression model where heteroskedasticity is corrected (see Table 3), represented as $\widehat{G D P}_{i}=1383.85+1.22765 \mathrm{X}_{1 \mathrm{i}}+4.37859 \mathrm{X}_{2 \mathrm{i}}+0.599315 \mathrm{X}_{3 \mathrm{i}} \quad-$ $14280.5 \mathrm{X}_{4 \mathrm{i}}$, the estimated model parameters in this case, shows that all the independent variables under study, namely, Revenue, Expenditure, Foreign Direct Investment and Exchange rate have significant positive effect on GDP when the Weighted Least Squares (WLS) method is used. Again, this result agrees [11].

On the test for structural change, the result of the multiple break point using the Bai-Perron test for the period 1961 to 2010 on Table 4 presents the break points as 1973, 1980, 1987, 1994 and 2001 with the corresponding models thus:

$\widehat{G D P}_{i}=$

$-54891+0.7509 \mathrm{X}_{1 \mathrm{i}}+2.9433 \mathrm{X}_{2 \mathrm{i}}+1.8054 \mathrm{X}_{3 \mathrm{i}}+78189.2 \mathrm{X}_{4 \mathrm{i}} ; 1961$

-1972 with 12 observations

Here, only Expenditure contributes to increase in GDP with $\mathrm{p}$-value $(\mathrm{P}=0.0000<0.05)$. This is period in the history of Nigeria where there was oil boom and political instability was the order of time culminating into civil war and the postwar effects. For the period 1973 to 1979 with 7 observations, the model for this structure is given as $\widehat{G D P}_{i}=$ $-80012.3+3.9833 \mathrm{X}_{1 \mathrm{i}}+0.1875 \mathrm{X}_{2 \mathrm{i}}+0.4712 \mathrm{X}_{3 \mathrm{i}}+121770.0 \mathrm{X}_{4 \mathrm{i}}$

This period marked the peak of oil boom, transition from military to civilian regime. Here, Exchange rate and Revenue had significant positive impact on GDP with $(\mathrm{P}<0.05)$.

For the third set that occurred from 1980 to 1986 with 7 observations (a period marked by government stringency measures and sudden change from civilian to military regime), the model for this structure is presented as $\widehat{G D P}_{i}=$ $-17436.7+2.2147 \mathrm{X}_{1 \mathrm{i}}-1.53714 \mathrm{X}_{2 \mathrm{i}}+0.3153 \mathrm{X}_{3 \mathrm{i}}+89707.2 \mathrm{X}_{4 \mathrm{i}}$

Here, the various changes influence the impact of these variables on GDP as Government Expenditure, Exchange rate, Revenue and FDI were all significant. However, Expenditure had negative relationship with the GDP.

For the structure 1987 to 1993 with seven (7) observations marked by Structural Adjustment Programme of the military regime, the model is $\widehat{G D P}_{i}=53468.8+1.8377 \mathrm{X}_{1 \mathrm{i}}+2.3545 \mathrm{X}_{2 \mathrm{i}}+0.4277 \mathrm{X}_{3 \mathrm{i}} \quad-$ $15156.9 \mathrm{X}_{4 \mathrm{i}}$

In this structure, only Revenue has significant positive effect on GDP with $\mathrm{P}$-value $(\mathrm{P}=0.0000<0.05)$.

For the period1994 to 2000 with seven (7) observations, the model for this structure is given as

$$
\begin{gathered}
\widehat{G D P}_{i}=1102236+3.2883 \mathrm{X}_{1 \mathrm{i}}- \\
0.9645 \mathrm{X}_{2 \mathrm{i}}+0.8958 \mathrm{X}_{3 \mathrm{i}}-34278.6 \mathrm{X}_{4 \mathrm{i}}
\end{gathered}
$$

This period marked the peak period of military rule in Nigeria and transition to another civil rule. Here, Revenue and FDI with $\mathrm{P}=0.0000<0.05)$ contributes significantly and positively to GDP. For the last break period of 2001 to 2010 with 7 observations, (a period of civilian regime with socio economic challenges including restiveness, terrorism and global gluts leading to various reforms), the model is represented as

$$
\begin{gathered}
\widehat{G D P}_{i}=-19448097- \\
0.05284 \mathrm{X}_{1 \mathrm{i}}+5.3699 \mathrm{X}_{2 \mathrm{i}}+0.6498 \mathrm{X}_{3 \mathrm{i}}+170050 \mathrm{X}_{4 \mathrm{i}}
\end{gathered}
$$

For the structure, Governments Expenditures and Exchange rate contributes to the increase in GDP with pvalue $(\mathrm{P}=0.0000<0.05)$.

Comparing the model with Heteroscedasticity and without Heteroscedasticity using the Akaike Information Criteria (AIC), it is clear that the $\mathrm{AIC}=138.04$ for model with correction for heteroskedasticity is by far less than the $\mathrm{AIC}=1511.838$ for the model without correction for heteroskedasticity, an indication that the model with correction for heteroskedasticity is preferable. This result is further collaborated by the coefficient of determination $\mathrm{R}^{2}=99.1 \%$ against $\mathrm{R}^{2}=98.91 \%$ for model with correction for heteroskedasticity and the model without correction for heteroskedasticity respectively.

The overall model using Bai-Perron multiple breakpoint test shows an $\mathrm{AIC}=29.663$ with $\mathrm{R}^{2}=99.6 \%$ showing that the structural breaks actually exist and this procedure provides a good modeling environment to predict the behavior of the variables when it is suspected that multiple breaks exist. This result agree with the work of [23].

\section{Conclusion}

This study tested for the presence of heteroskedasticity using the White test. It identified the presence of heteroskedasticity and corrected it using the Weighted Least Squares method. It further determined the presence of multiple break points using Bai and Perron approach and examined the effect of government Revenue, Expenditure, Foreign Direct Investment (FDI) and Exchange rate on Nigerian Gross Domestic Product (GDP) for the period 1961 to 2010. The presence of heteroskedasticity and persistent structural break is not a good indicator for economic development as it posits instability in economic development.

Similarly, the estimated parameters using model with no correction or adjustment for constant mean and variance over time change shows that Revenue, Expenditure, Foreign Direct Investment significantly affect GDP positively while the constant term and Exchange rate negatively affect the GDP.

Furthermore, it is noticeable that the model with correction for heteroskedasticity appears more stable than the model with the presence of heteroskedasticity.

Consequently, this study supports growing evidence that government Revenue, Expenditure, Foreign Direct Investment and Exchange rate has strong relationship with and exerts significant effect on Nigerian Gross Domestic Product (GDP) in the presence of stable policies. Therefore, government Revenue, Expenditure, Foreign Direct Investment and Exchange rate are important variables in 
explaining Nigeria's GDP and adequate control measures must be put in place to ensure control that will enhance stable economic growth.

\section{Appendix}

Table A1. Data of Nigeria's Economic Variables for the Period 1961-2010.

\begin{tabular}{|c|c|c|c|c|c|}
\hline Year & GDP & REV & EXP & FDI & Exchrate \\
\hline 1961 & 2361.2 & 223.654 & 163.898 & 339.428 & 0.7143 \\
\hline 1962 & 2597.6 & 477.704 & 167.482 & 347.256 & 0.7143 \\
\hline 1963 & 2755.8 & 498.188 & 183.514 & 337.072 & 0.7143 \\
\hline 1964 & 2894.4 & 554.412 & 220.338 & 378.66 & 0.7143 \\
\hline 1965 & 3110 & 654.344 & 236.42 & 429.302 & 0.7143 \\
\hline 1966 & 3374.8 & 612.88 & 255.144 & 536.774 & 0.7143 \\
\hline 1967 & 2752.6 & 654.344 & 258.014 & 568.168 & 0.7143 \\
\hline 1968 & 2656.2 & 569.528 & 349.892 & 485.638 & 0.7143 \\
\hline 1969 & 3549.3 & 755.956 & 556.194 & 422.118 & 0.7143 \\
\hline 1970 & 5281.1 & 634 & 903.9 & 635.992 & 0.7143 \\
\hline 1971 & 6650.9 & 1168.8 & 997.2 & 885.668 & 0.7143 \\
\hline 1972 & 7187.5 & 1405.1 & 1463.6 & 1293.4 & 0.6955 \\
\hline 1973 & 8630.5 & 1695.3 & 1529.2 & 1434.2 & 0.6579 \\
\hline 1974 & 18823.1 & 4537.4 & 2740.6 & 2278.4 & 0.6579 \\
\hline 1975 & 21475.24 & 5514.7 & 5942.6 & 5794.8 & 0.629875 \\
\hline 1976 & 26655.78 & 6765.9 & 7856.7 & 4925.5 & 0.61585 \\
\hline 1977 & 31520.34 & 8042.4 & 8823.8 & 6751.1 & 0.626533333 \\
\hline 1978 & 34540.1 & 7371 & 8000 & 7630.7 & 0.646616667 \\
\hline 1979 & 41974.7 & 10912.4 & 7406.7 & 6064.4 & 0.60595 \\
\hline 1980 & 49632.32 & 15233.5 & 14968.5 & 10836.8 & 0.595741667 \\
\hline 1981 & 47619.66 & 13290.5 & 11413.7 & 14186.7 & 0.546358333 \\
\hline 1982 & 49069.28 & 11433.7 & 11923.2 & 11023.3 & 0.610025 \\
\hline 1983 & 53107.38 & 10508.7 & 9636.5 & 8206.4 & 0.672866667 \\
\hline 1984 & 59622.53 & 11253.3 & 9927.6 & 7502.5 & 0.724141667 \\
\hline 1985 & 67908.55 & 15050.4 & 13041.1 & 9088 & 0.764941667 \\
\hline 1986 & 69146.99 & 12595.8 & 16223.7 & 11720.8 & 0.89375 \\
\hline 1987 & 105222.84 & 25380.6 & 22018.7 & 8920.6 & 2.020575 \\
\hline 1988 & 139085.3 & 27596.7 & 27749.5 & 30360.6 & 4.017941667 \\
\hline 1989 & 216797.54 & 53870.4 & 41028.3 & 31192.8 & 4.536733333 \\
\hline 1990 & 267549.99 & 98102.4 & 60268.2 & 57971.2 & 7.391558333 \\
\hline 1991 & 312139.74 & 100991.6 & 66584.4 & 109886.1 & 8.037808333 \\
\hline 1992 & 532613.83 & 190453.2 & 92797.4 & 121535.4 & 9.909491667 \\
\hline 1993 & 683869.79 & 192769.4 & 191228.9 & 205611.7 & 17.298425 \\
\hline 1994 & 899863.22 & 201910.8 & 160893.2 & 218770.1 & 22.05105833 \\
\hline 1995 & 1933211.55 & 459987.3 & 248768.1 & 206059.2 & 21.8861 \\
\hline 1996 & 2702719.13 & 523597 & 337217.6 & 950661.4 & 21.8861 \\
\hline 1997 & 2801972.58 & 582811.1 & 428215.2 & 1309543.4 & 21.8861 \\
\hline 1998 & 2708430.86 & 463608.8 & 487113.4 & 1241662.7 & 21.8861 \\
\hline 1999 & 3194014.97 & 949187.9 & 947690 & 751856.7 & 21.8861 \\
\hline 2000 & 4582127.29 & 1906159.7 & 701059.4 & 1188969.8 & 92.69335 \\
\hline 2001 & 4725086 & 2231600 & 1018025.6 & 1945723.3 & 102.1052083 \\
\hline 2002 & 6912381.25 & 1731837.5 & 1018155.8 & 1867953.85 & 111.943325 \\
\hline 2003 & 8487031.57 & 2575095.9 & 1225965.9 & 1744177.677 & 120.9701667 \\
\hline 2004 & 11411066.91 & 3920500 & 1426200 & 3087886.393 & 129.3565333 \\
\hline 2005 & 14572239.12 & 5547500 & 1822100 & 4602781.54 & 133.5004 \\
\hline 2006 & 18564594.73 & 5965101.9 & 1938002.5 & 7246534.8 & 132.147 \\
\hline 2007 & 20657325 & 5715600 & 2450896.7 & 7324680.63 & 128.6516 \\
\hline 2008 & 24296329.29 & 7866590.1 & 3240820 & 8309758.32 & 125.8331 \\
\hline 2009 & 24794238.66 & 4844592.342 & 3452990.8 & 10161490.12 & 118.5669167 \\
\hline 2010 & 33984754.13 & 7303671.55 & 4194217.88 & 8356385.57 & 148.9017417 \\
\hline
\end{tabular}

Source: CBN Bulletin.

[2] Devarajan, S., Swaroop, V. and Zou, H. (1996). The Composition of Public Expenditure and Economic Growth. Journal of Monetary Economics. 37: 313-344.

\section{References}

[1] National Bureau of Statistics. (NBS, 2015). Gross Domestic Product Rebasing Publication.

[3] Ogbulu, O. M. (2009). Capital Market Development and Economic Growth in Nigeria: Application of Co-integration and Causality Tests. Journal of Finance, Banking and Investment. 3 (1): 56-79. 
[4] Bleaney, M., Gemmell, N. and Kneller, R. (2001). Testing the Endogenous Growth Model: Public Expenditure, Taxation and Growth Over the Long-run. The Canadian Journal of Economics. 34 (1): 36-57.

[5] Ayinde, K., Kuranga, J. and Lukman, A. F. (2015). Modeling Nigerian Government Expenditure, Revenue and Economic Growth: Co-integration, Error Correction Mechanism and Combined Estimators Analysis Approach. Asian Economic and Financial Review. 5 (6): 858-867.

[6] Nworji, I. D., Okwu, A. T., Obiwuru, T. C. and Nworji, L. O. (2012). Effects of Public Expenditure on Economic Growth in Nigeria: A Disaggregated Time Series Analysis. International Journal of Management Sciences and Business Research. 1 (7): 1-13.

[7] Agbonkhese, A. O. and Asekome, M. O. (2014). Impact of Public Expenditure on the Growth of Nigerian Economy. European Scientific Journal. 10 (28): 219-229.

[8] Adeniran, J. O., Yusuf, S. A. and Adeyemi, O. A. (2014). The Impact of Exchange Rate Fluctuation on the Nigerian Economic Growth: An Empirical Investigation. International Journal of Academic Research in Business and Social Sciences. 4 (8): 224-233.

[9] Aslam, A. L. M. (2016). Impact of Exchange Rate on Economic Growth in Sri Lanka. World Scientific News. 54: 252-266.

[10] Ugochukwu, U. S., Okore, O. A. and Onoh, J. O. (2013). The Impact of Foreign Direct Investment on the Nigerian Economy. European Journal of Business and Management. 5 (2): 25-33.

[11] Adeleke, K. M., Olowe, S. O. and Fasesin, O. O. (2014). Impact of Foreign Direct Investment on Nigeria Economic Growth. International Journal of Academic Research in Business and Social Sciences. 4 (8): 234-242.

[12] Rahman, A. (2015). Impact of Foreign Direct Investment on Economic Growth: Empirical Evidence from Bangladesh. International Journal of Economic and Finance. 7 (2): 178-185.

[13] Greene, W. H. (2002). Econometrics Analysis. 5th Edition, Prentice Hall. Pp 225-229.
[14] Wooldridge, J. M. (2009). Introductory Econometrics: A Modern Approach. 5th Edition, South-Western Cengage Learning. Pp 280-287.

[15] Bai, J. and Perron, P. (1998). Estimating and Testing Linear Models with Multiple Structural Changes. Econometrica. 66 (1): 47-78.

[16] Kleibergen, F. (2002). Pivotal Statistics for Testing Structural Parameters in Instrumental Variables Regression. Econometrica. 70 (5): 1781-1803.

[17] Antoshin, S. Berg, A. and Souto, M. (2008). Testing for Structural Breaks in Small Samples. International Monetary Fund Working Paper. 29pp.

[18] Bai, J. and Perron, P. (2006). Multiple Structural Change Models: A Simulation Analysis in Econometric Theory and Practice. Frontier of Analysis and Applied Research. 30pp.

[19] Chen, B. and Hong, Y. (2012). Testing for Smooth Structural Changes in Time Series Models via Nonparametric Regression. Econometrica. 80 (3): 1157-1183.

[20] Hansen, B. E. (2001). The New Econometrics of Structural Change: Dating Breaks in U.S. Labor Productivity. Journal of Economic Perspectives. 15 (4): 117-128.

[21] Zeileis, A., Leisch, F. and Hornik, K. (2001). Strucchange: An $\mathrm{R}$ package for Testing for Structural Change in Linear Regression Models. Journal of Statistical Software. 7 (2): 138.

[22] Allaro, H. B., Kassa, B. and Hundie, B. (2011). A Time Series Analysis of Structural Break Time in the Macroeconomic Variables in Ethiopia. African Journal of Agricultural Research. 6 (2): 392-400.

[23] Perron, P. (1989). The Great Crash, the Oil Price Shock and the Unit Root Hypothesis. Econometrica. 57: 1361-1401.

[24] Onel, G. (2005). Testing for Multiple Structural Breaks: An Application of Bai-Perron Test to the Nominal Interest Rate and Inflation in Turkey. D. E. U. II. B. F. Dergisi. 20 (2): 8193. 